many archaeologists are interested in epistemology and any journal which attempts to investigate how we know archaeologically, will find a large and enthusiastic audience. This journal is aimed at those who see archaeology as 'anthropology or nothing' and there are many of them. One final point; the editor hopes the JAA will become a "medium for international communication and debate" but this may prove difficult in a format where only $20-40$ page articles appear with no short notes, no letters to the editor and no editorial comments. The success of the JAA may well be proportional to the amount of editorial energy expended.

John Parkington is at the Department of Archaeology, University of Cape Town.

\section{Plastic aspects}

\section{Paul Calvert}

Carbohydrate Polymers: Scientific and

Technological Aspects of Industrially

Important Polysaccharides.

Editors J.M.V. Blanshard and

J.R. Mitchell.

Applied Science. 4/yr. 199.

Polymer Photochemistry:

An International Journal.

Editor N.S. Allen.

Applied Science. 4/yr. 1111 .

Cellular Polymers: An International

Journal.

Editor J.M. Buist.

Applied Science. 6/yr. fl00.

THESE three journals are from a publisher which has in recent years produced a great number of books and reviews in the area of applied polymer science. Although they have a similar format and cost, the three differ significantly in the type of papers they publish, particularly as to where they fit in the spectrum from science to technology. In each case the time from receipt to publication is six months to a year, it cannot really be less in a quarterly publication.

The editors of Carbohydrate Polymers are at the School of Agriculture of the University of Nottingham. The university majority on the editorial board is reflected in the bias towards papers which describe fundamental studies of structure and properties of polysaccharides. In addition, there is a regular set of patent summaries and a book review. The established journal in this field is Carbohydrate Research which is published by the related company Elsevier. A co-operative arrangement has been set up between the two but it is not clear how this operates. A separate forum for polymer papers is welcome in that Carbohydrate Research is a daunting collection of studies on sugars with the occasional polymeric nugget.

The mix of articles so far has a pre- dominance of studies of physical structure and properties including crystal structures, chain conformations and viscosity studies with fewer purely chemical papers. Polysaccharides are by far the commonest polymers in the world on a weight basis but they have become minor industrially, compared to synthetic polymers and have never been as glamorous subjects for study as proteins and nucleic acids. With the leap in oil prices it looked for a while as if they might come into their own as plastics, though this now looks less likely. Nonetheless this journal is a useful focus for work in this field which still has great potential.

Polymer Photochemistry is edited by Norman Allen of Manchester Polytechnic with a largely academic editorial board. Most of the manuscripts originate in universities or government laboratories. In addition occasional reviews and book reviews are published. Polymer photochemistry is not as yet a completely defined area of study. The two fields where photochemistry is of particular significance to polymers are in degradation and its prevention and in photoinitiation of polymerization. The majority of papers so far seem to be concerned with aspects of

\section{CELLOLAR POLYMERS}

photo-oxidation, photodegradation or the action of light stabilizers.

There is already a specialized journal of polymer degradation to which these papers could also go (Polymer Degradation and Stability, reviewed in 1981). Both photopolymerization and photostabilization systems tend to be very specific commercial materials so it is not really clear that there is enough common ground to support a new journal. This one will have to cut its own niche in order to survive.

Cellular Polymers is a revised version of the European Journal of Cellular Plastics. Its concern, contrary to what might immediately suggest itself to readers of Nature, is all aspects of polymer foams such as are widely used in furniture and in building insulation. The editorial board is largely drawn from industrial and government laboratories and the papers are mostly technological: processing, properties and applications of commercial systems. The editor sees this range also extending into discussions of health and safety testing of these materials and of their markets. In addition to papers there are book reviews, conference reports and a reproduction of Foam Abstracts from RAPRA. Thus this is a journal very much aimed at industrial and academic plastics engineers.

Paul Calvert is in the School of Chemistry and Molecular Sciences, University of Sussex.

\section{New ways with timber}

Gavin S. Hall

\section{Journal of Wood Chemistry} and Technology.

Editors O.C. Johnson and

L.R. Schroeder.

Dekker, 4/yr. \$75.

A JOURNAL which concentrates on the raw materials for paper manufacture must surely start with bonus points in the justification league for new journals. The idea of positive feedback is somehow satisfying in this often maligned sphere. Such a journal is this New York-based venture whose issues so far deal preponderantly with basic but essentially exploitable, aspects of wood pulp production, bleaching etc. This field is only part of the claimed scope of this journal which is dedicated to "rapid communication of research on chemistry of wood and wood components and chemical phenomena important to wood technology'".

Whether it achieves the former aim is difficult to judge but it has already attracted a wide authorship, mainly from North America but also from several other countries. The impressive Editorial Advisory Board is similarly international in constitution. If the UK is representative, this journal is not as widely known outside North America as it apparently deserves. But then UK activity in this research field is at a very low ebb and is probably not a good standpoint from which to view the resurgence of interest and activity, in treerich countries, towards all aspects of the chemical utilization of wood.

Historically, the physical/mechanical aspects of wood science and technology have had publication outlets separate from those of pulp and paper chemistry. The recent amalgamation of two of the main journals in the physical and mechanical field and the sickly state of a third, suggest an overcapacity. The scope of this new journal bridges the divide and the contributions published to date reflect the chemical utilization bias.

The swing back to wood as a renewable resource, albeit on a more technologically sophisticated level than formerly, must give this journal a good chance of longterm success as long as it fulfils its aims. Its clear, no-nonsense presentation, its policy of free and rapid publication of contributions, its concentration on researchderived scientific papers and its modest price (particularly to individual subscribers) augur well for the future.

Gavin S. Hall is Head of Technology at the Timber Research and Development Association, High Wycombe, UK. 